\title{
Prevalence of schistosomiasis among school aged children in Altakamol area, Khartoum state, Sudan
}

\begin{abstract}
Schistosoma haematobium is a causative agent of urinary Schistosomiasis and Schistosoma mansoni causing intestinal Schistosomiasis which is wide spread worms in the world and are considered a foremost health problem in the Sudan. Cross sectional study was carried out among school aged children in Altakamol area - Khartoum state, from February to March 2017 to recognize the prevalence of Schistosoma haematobium and Schistosoma mansoni among school children in the area. One hundred sixty samples were collected randomly using random systematic manner including, 80samples from male and 80 from female. Forty urine samples and 40 stool samples were collected form student at class 3 , 5, 6 and 7 and examined macroscopically and microscopically. The data collected through questionnaire. Of the 160 participants 6 infected with Schistosoma hematobium and 2 were infected with Schistosoma mansoni. The overall prevalence of Schistosomiasis in the area was $5 \%$.Significant association was observed between gender and age and acquiring Schistosoma infection $(\mathrm{p}=0.01)$. Further study among school children with large sample size is needed.
\end{abstract}

Keywords: urinary and intestinal schistosomiasis, school aged children, Khartoum, Sudan
Volume 8 Issue 5 - 2020

\author{
Trig Mohamed Elfaki,' Mosab Nouraldein \\ Mohammed Hamad, ${ }^{2}$ Essam Zarrug,' Hussein \\ Omer Musa Mohammed, ${ }^{3}$ Sally Hassan \\ Mohammed,' Randa Alaageb Haj Ahmad,' \\ Rabab Mohammed Eltaher,' Tasneem \\ Isamaldein Ahamed Karrar \\ 'Parasitology and Medical Entomology Department, Program \\ of Medical laboratory Sciences, Academy of Health Sciences, \\ Khartoum, Sudan \\ 2Phylum of Medical Parasitology, Medical Laboratory Sciences \\ Department, Faculty of Health Science, Elsheikh Abdallah Elbadri \\ University, Sudan \\ ${ }^{3}$ Faculty of Medical Laboratory Sciences, Alneelain University, \\ Sudan
}
Correspondence: Mosab Nouraldein Mohammed Hamad, Phylum of Medical Parasitology, Medical Laboratory Sciences Department, Faculty of Health Science, Elsheikh Abdallah Elbadri University, Berber, Sudan, Email musab.noor3@gmail.com

Received: September 14, 2020 | Published: October 02, 2020

\section{Background}

Schistosomiasis is a parasitic disease caused by flukes of the genus Schistosoma. After malaria and intestinal helminthiasis, schistosomiasis is the third most devastating tropical disease in the world, being a major source of morbidity and mortality in developing countries of Africa, South America, the Caribbean, the Middle East, and Asia. ${ }^{1}$ Around $25 \%$ of Earth populaces are infected with parasitic helminthes and most of them are existing in Africa. ${ }^{2}$ More than 207 million people of which $85 \%$ living in Africa, are infected with schistosomiasis, ${ }^{1}$ and an estimated 700 million people are at risk of infection in 76 countries where the disease is considered endemic, as their agricultural work, domestic chores, and recreational activities expose.

Sometimes referred to as bilharzias, bilharzias is, or snail fever, schistosomiasis was discovered by Theodore Bilharz, a German surgeon working in Cairo, who first identified the etiological agent Schistosoma hematobium in 1851 ,in infested water. ${ }^{1,3}$ In tropical and subtropical regions, soil-transmitted worms are extensively distributed, counting Ascarislumbricoides, Trichuristrichiura and hookworms, collected with filarial nematodes and schistosomes. ${ }^{4}$

Most human schistosomiasis is caused by S. haematobium, S. mansoni, and S. japonicum. Less prevalent species, such as S. mekongi and $\mathrm{S}$ intercalatum, may also cause systemic human disease. Less importantly, other schistosomes with avian or mammalian primary hosts can cause severe dermatitis in humans. Freshwater snails act as the vector, releasing larval forms of the parasite into water. These larvae subsequently penetrate the skin of people who are in that water (e.g. fishermen). The larvae develop into adult schistosomes in the body, and are either released through urine or cause an immune reaction (if they remain in the body). Urinary Schistosomias also associated with spread of many diseases, such as enteric fever, while there was no relation between Schistosoma mansoni and salmonellosis. ${ }^{5}$

In Sudan Archibald (1933) thought that Schistosomiasis started as far back as 2600 B.C. he mentioned that Schistosomiasis has been introduced into Sudan through economic and political contact with Egypt, also he suggested that the thousands of pilgrims from West Africa flowing through the country, to and from Mecca, played an important role in the disease transmission. Schistosomiasis in Sudan is a second major public health problem. It leads to 28 million at risk, 5824000 infected and 9450 deaths every year (2000 estimates). We select school aged children because many studies showed high prevalence of intestinal parasitic infection among this group of people. According to Hamad et al; the prevalence of intestinal parasite in Berber area primary schools was very high $(87.2 \%){ }^{6}$

\section{S. haematobium}

Where the reports from the ministry of federal health confirm Gezira state in the forefront of states in the rate of infection, especially the rate was $(54 \%)$, followed by the states of Kassala, locality New halfa $(2.45 \%)$, Sennar , locality Dinder(3.38\%), Gedaref, locality Fao, (4.37\%), White Nile State, Assalaya (5.35\%) and finally Blue Nile state locality Rosaries(6.32\%). Study done by Hamad et al in Khelawa village, River Nile State, Sudan; showedthat; $32.5 \%$ of school aged children were infected with Schistosoma haematobium. ${ }^{7}$

Dissimilar all other pathologically significant flukes, schistosomes are not hermaphroditic, but have discrete sexes. The adult worms are 
$1-2 \mathrm{~cm}$ long with a cylindrical body that structures double terminal suckers, a complex tegument, a blind digestive tract, and reproductive structures. The male's body forms a hollow or gynaecophoric channel, in which it grips the longer and thinner female. As enduringly embraced couples, the schistosomes living within the perivesical (S. haematobium) or mesenteric (other species) venous plexus. Schistosomes feed on blood particles through anaerobic glycolysis. ${ }^{8}$ Persons are infested with $\mathrm{S}$. hematobium through monotonous farming, domestic, professional, and recreational activities, which expose them to infested water. ${ }^{9}$

\section{S. mansoni}

Depending on the statistic of the national health medical services, the S. masoni spread in many Sudanese areas include, Khartoum, Gezira especially in the local El-managil, Kassala, Kordofan, Darfur and Blue Nile. Study done by Siddig et al, recommended to use Formol Ether concentration technique for detection of intestinal parasites ${ }^{10}$ as Schistomamansoni. Further study among school children with large sample size are needed and using different diagnostic methods.

\section{Rationale}

Schistosoma as it causing liver fibrosis and urinary bladder carcinoma as it's one of the complications; we will do this research to identify the common species in the school age children to reach better way for prevention and treatment.

\section{Objectives}

\section{General objectives:}

To detect the Prevalence of Schistosomiasis in Altakamol area.

\section{Specific objectives:}

a. To study Schistosomiasis at Altakamol area among school children in 2017.

b. To assess the association between rate of infection and gender.

\section{Materials and methods}

Study design: Descriptive cross sectional study.

Study area: Altakamol area in Khartoum state in Sudan

Study population: School aged children in Altakamol area

Study period: February to March 2017

Sample size: 160 participants.

\section{Method}

Urine and stool specimens collected from each participants were examined for S. schistosoma hematobium and S. mansoni by direct parasitological methods (examination of urine sediment and wet mount).

\section{Data collection}

Data collected through well designed questionnaire contained all the required information about every participant.

\section{Data analysis}

Data analyzed with statistical package for social science (SPSS) version 16 .

\section{Ethical approval}

Study was approved by ethical committee at, Academy of Health Sciences.

\section{Result}

8 participants were infected with schistosomiasis, 6 were infected with S. hematobium and 2 with S. mansoni. The total prevalence of Schistosomiasis in the area was 5\%. Significant connotation was detected between gender and age and getting Schistosoma infection $(\mathrm{p}=0.01)($ Tables 1-3).

Table I Shows the prevalence of schistosomiasis

\begin{tabular}{llllll}
\hline & & Frequency & Percent & Valid Percent & Cumulative Percent \\
\hline \multirow{2}{*}{ Valid } & negative & 152 & 95 & 95 & 95 \\
& $\begin{array}{l}\text { positive } \\
\text { Total }\end{array}$ & 8 & 5 & 5 & 100 \\
& 160 & 100 & 100 & \\
\hline
\end{tabular}

Table 2 Show the schistosoma in urine

\begin{tabular}{llllll}
\hline & & Frequency & Percent & Valid Percent & Cumulative Percent \\
\hline \multirow{3}{*}{ Valid } & negative & 154 & 96.2 & 96.2 & 96.2 \\
& positive & 6 & 3.8 & 3.8 & 100 \\
& Total & 160 & 100 & 100 & \\
\hline
\end{tabular}

Table 3 Show the schistosoma in stool

\begin{tabular}{llllll}
\hline & & Frequency & Percent & Valid Percent & Cumulative Percent \\
\hline \multirow{3}{*}{ Valid } & negative & 158 & 98.8 & 98.8 & 98.8 \\
& positive & 2 & 1.2 & 1.2 & 100 \\
& Total & 160 & 100 & 100 & \\
\hline
\end{tabular}




\section{Discussion}

Our study showed lower prevalence of S. hematobium $(5 \%)$ than the Study done by Hamad et al in Khelawa village, River Nile State, Sudan; showed that; $32.5 \%$ of school aged children infected with Schistosoma hematobium, that attributed to many technical ( laboratory methods, sample size, personnel experience ) and nontechnical factors ( levels of sanitation and health education).

\section{Conclusion and recommendations}

Our study revealed that low prevalence of schistosomiasis among the participants $(5 \%)$.Low prevalence may be attributed to low sensitivity of direct parasitological methods.

\section{Acknowledgments}

None.

\section{Conflicts of interest}

Authors declare that there is no conflict of interest.

\section{References}

1. Schistosomiasis, Fact Sheet No 115. World Health Organization; 2010.

2. Hotez PJ, Alvarado M, Basanez MG, et al. The global burden of disease study 2010: interpretation and implications for the neglected tropical diseases. PLoS Negl Trop Dis. 2014;8(7):e2865.
3. Poliomyelitis in Tajikistan: first importation since Europe certified polio-free Schistosomiasis. Weekly Epidemiological Record. 2010;85(18):157-164.

4. Karagiannis-Voules DA, Biedermann P, Ekpo UF, et al. Spatial and temporal distribution of soil-transmitted helminth infection in sub-Saharan Africa: a systematic review and geostatistical meta-analysis. Lancet Infect Dis. 2015;15(1):74-84.

5. Mohamed AMA, Hamad MNM. Relationship between intestinal Schistosomiasis and enteric fever among Sudanese patients, New Halfa Town, KassalaState, Sudan. J Microbiol Exp. 2020;8(3):109-113.

6. Hamad MNM, Mokhtar AA, Alameldin M, et al. Prevalence of intestinal parasitic infections among school aged children in Berber locality, River NileState, Sudan 2017. J Microbiol Exp. 2019;7(2):85-86.

7. Mosab N M H, Esraa A S A, Hala Alaa H O, et al. Prevalence of Urinary Schistosomiasis among School Aged Children in Khelawa Village, River Nile State, Sudan, 2017. Res Med Eng Sci. 2018;3(2):220-221.

8. Rumnajek FD. Biochemistry and physiology. In: The biology of Schistosomes. Rollinson D, Simpson AJD, editors. London, UK: Academic Press; 1987. 163-183 p.

9. Schistosomiasis, Key facts. WHO; 2020.

10. Hussein Sharif Siddig, Imad Abdelgalil Mohammed, Mosab Nouraldein Mohammed e al. Prevalence of Intestinal Parasites among Selected Group of Primary School Children in Alhag Yousif Area, Khartoum, Sudan. International Journal of Medical Research \& Health Sciences. 2017;6(8):125-131. 